\title{
Mobility Changes, Teleworking, and Remote Communication during the COVID-19 Pandemic in Chile
}

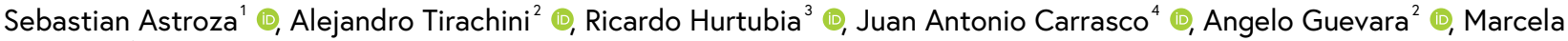 \\ Munizaga $^{2}$ (1), Macarena Figueroa ${ }^{5}$ (D), Valentina Torres $^{5}$ (1) \\ ${ }^{1}$ Department of Industrial Engineering, Universidad de Concepción and Instituto Sistemas Complejos de Ingeniería (ISCI) , 2 Civil Engineering Department, \\ Universidad de Chile and Instituto Sistemas Complejos de Ingeniería (ISCI) , ${ }^{3}$ School of Architecture \& Department of Transport Engineering and Logistics, \\ Pontificia Universidad Católica de Chile and Instituto Sistemas Complejos de Ingeniería (ISCI) , ${ }^{4}$ Department of Civil Engineering, Universidad de Concepción \\ and Instituto Sistemas Complejos de Ingeniería (ISCI) , ${ }^{5}$ Department of Industrial Engineering, Universidad de Concepción \\ Keywords: coronavirus, mobility, travel behavior, covid-19 \\ https://doi.org/10.32866/001c.13489
}

Transport Findings

\begin{abstract}
Results from a mobility survey from Chile during the COVID-19 pandemic show a decrease of $44 \%$ of trips in Santiago, with metro (55\%), ride-hailing (51\%), and bus (45\%) presenting the highest reduction. Modes with the lowest reduction are motorcycle (28\%), auto (34\%), and walking (39\%). While $77 \%$ of workers from low-income households had to go out and work, $80 \%$ of workers from highincome households worked from home. Other important factors that correlate with teleworking are gender, educational level, employment status, and occupation. Regarding the number of trips for purposes other than work, significant factors are gender, age, and employment status.
\end{abstract}

\section{RESEARCH QUESTIONS AND HYPOTHESES}

This article attempts to measure and understand the difference in the number of trips per purpose and mode between a normal week and a week during the COVID-19 pandemic in Santiago de Chile by analyzing the behaviour of different population segments.

\section{METHODS AND DATA}

Results are based on an online survey. Sample: 4,395 adults living in Chile. The survey was opened during the week March 23-29, 2020, and distributed via online forums, social media, email, messaging apps, and one public transportation app (Transapp). Ours is a convenience sample without poststratification, which is therefore not necessarily representative of the country or at the city level. Nevertheless, most income, age, gender, and modal strata are covered, which allows inferring impacts conditional on those groups, up to inevitable limitations imposed by self-selection in online surveys, mainly due to heterogeneity on internet-access. Table 1 shows the general descriptive statistics of our sample: $48 \%$ of respondents belong to households with a monthly income lower than 1,180 USD. Median household income in Chile was 931 USD in $2017^{1}$ (INE 2018), which suggests a likely underrepresentation of low-income households. We also see an overrepresentation of females, since $59.1 \%$ of respondents are women, while this figure is $48.9 \%$ in the population. 
Table 1: Sample description $(\mathrm{n}=4,395)$

\begin{tabular}{|c|c|c|}
\hline Variable & Number of people & Percentage \\
\hline \multicolumn{3}{|l|}{ Gender } \\
\hline Male & 2,598 & 59.1 \\
\hline Female & 1,748 & 39.8 \\
\hline Other & 15 & 0.3 \\
\hline Prefer not to answer & 34 & 0.8 \\
\hline \multicolumn{3}{|l|}{ Age range } \\
\hline Between 18 and 25 years old & 1,024 & 23.3 \\
\hline Between 26 and 35 years old & 1,410 & 32.1 \\
\hline Between 36 and 45 years old & 1,048 & 23.8 \\
\hline Between 46 and 60 years old & 688 & 15.7 \\
\hline Older than 60 & 225 & 5.1 \\
\hline \multicolumn{3}{|l|}{ Household income (USD/month) } \\
\hline Less than 355 & 306 & 7.0 \\
\hline Between 355 and 710 & 885 & 20.1 \\
\hline Between 710 and 1,180 & 722 & 16.4 \\
\hline Between 1,180 and 1,775 & 582 & 13.2 \\
\hline Between 1,775 and 2,367 & 441 & 10.0 \\
\hline Between 2,367 and 3,550 & 456 & 10.4 \\
\hline More than 3,550 & 571 & 13.0 \\
\hline Not reported & 432 & 9.8 \\
\hline \multicolumn{3}{|l|}{ City } \\
\hline Santiago (greater urban area) & 3,222 & 73.3 \\
\hline Concepción (greater urban area) & 380 & 8.6 \\
\hline Valparaíso (greater urban area) & 144 & 3.3 \\
\hline Rest of the country & 644 & 14.8 \\
\hline \multicolumn{3}{|l|}{ Employment status } \\
\hline Full-time worker & 2,461 & 56.0 \\
\hline Part-time worker & 309 & 7.0 \\
\hline Self-employed & 427 & 9.7 \\
\hline Unemployed student & 672 & 15.3 \\
\hline Unemployed (not a student), including homemakers & 526 & 12.0 \\
\hline
\end{tabular}

We asked for the number of trips performed by mode and purpose during two consecutive weeks:

Week 1 (W1): March 9 (Monday) to March 15 (Sunday), 2020

Week 2 (W2): March 16 (Monday) to March 22 (Sunday), 2020

Week 1 is considered "normal", while Week 2 can be regarded as the first week of a nationwide response to the COVID-19 pandemic in Chile. It is immediately after the government declared suspension of classroom lessons at all levels on Sunday March $15^{\text {th }}$ (Álvarez et al. 2020). Also, in several job sectors teleworking was adopted on Week 2 , encouraged by the public authority. 
A binary probit (BP) model and a linear regression (LR) model are estimated jointly to examine the factors affecting workers' mobility behaviour in the greater urban area of Santiago during the COVID-19 pandemic. The two alternatives in the BP model choice-set are: (1) Work from home during Week 2 and (2) Work away from home during Week 2. Alternative 2 is used as the base (or reference) alternative. The dependent variable in the LR model corresponds to the difference between the number of trips for purposes other than work or study (shopping, errands, medical, leisure) in Week 2 and Week 1. Both decisions, workplace (or "teleworking status") and the difference in the number of trips for other purposes are estimated jointly through the inclusion of a correlation parameter between the error terms. Regarding endogenous effects, teleworking is modelled as a dummy variable to influence the difference in the number of trips purposes other than work.

\section{FINDINGS}

\section{MOBILITY CHANGES}

Figure 1 depicts the number of trips per mode for the Santiago de Chile subsample, which is $73 \%$ of our sample. The overall reduction of trips was $44 \%$. Modes that presented the highest reduction are metro (55\%), ride-hailing (e.g., Uber, Cabify, and Didi, 51\%) and bus (45\%). On the other hand, modes with the lowest reduction are those that are considered personal, such as motorcycle (28\%), auto (34\%) and walking (39\%). As an external validation, the Ministry of Transportation of Chile reported that public transportation smartcard transactions diminished $53 \%$ and $37 \%$ for metro and buses, respectively, during Week $2^{2}$, very close to our survey results (55\% metro and $45 \%$ buses). Regarding trips by purpose, we can see a $43 \%, 73 \%$, and 38\% trip reduction during Week 2 for work, study/school, and other purposes, respectively.

\section{TELEWORK (OR TELECOMMUTING)}

Figure 2 presents the telecommuting status of survey respondents during Week 2. Three-quarters of low-income workers (less than $710 \mathrm{USD} /$ month) in the sample had to go out and work during the COVID-19 outbreak in Chile. On the other hand, $80 \%$ of high-income workers did it from home.

\section{REMOTE COMMUNICATION}

We asked if survey respondents communicated remotely through text, voice, and video during Week 1 and Week 2 with family members, friends, neighbours, workmates, and classmates. Figure 3 presents the remote communication increment between Weeks 1 and 2. Remote communication increased on almost all fronts. Texting and calls increased $1 \%$ to $8 \%$, except communication between neighbours, in which case texts increased by $17 \%$

2 https://www.latercera.com/nacional/noticia/santiago-y-regiones-sufren-fuerte-baja-en-los-viajes-traslados-en-metro-merval-y-biotren-sereducen-a-la-mitad/SUL6KV476RD45E2N7K3FAIFZWY/, accessed May $14^{\text {th }}, 2020$ 
Figure 1: Total trips for Santiago sample $(n=3,222)$

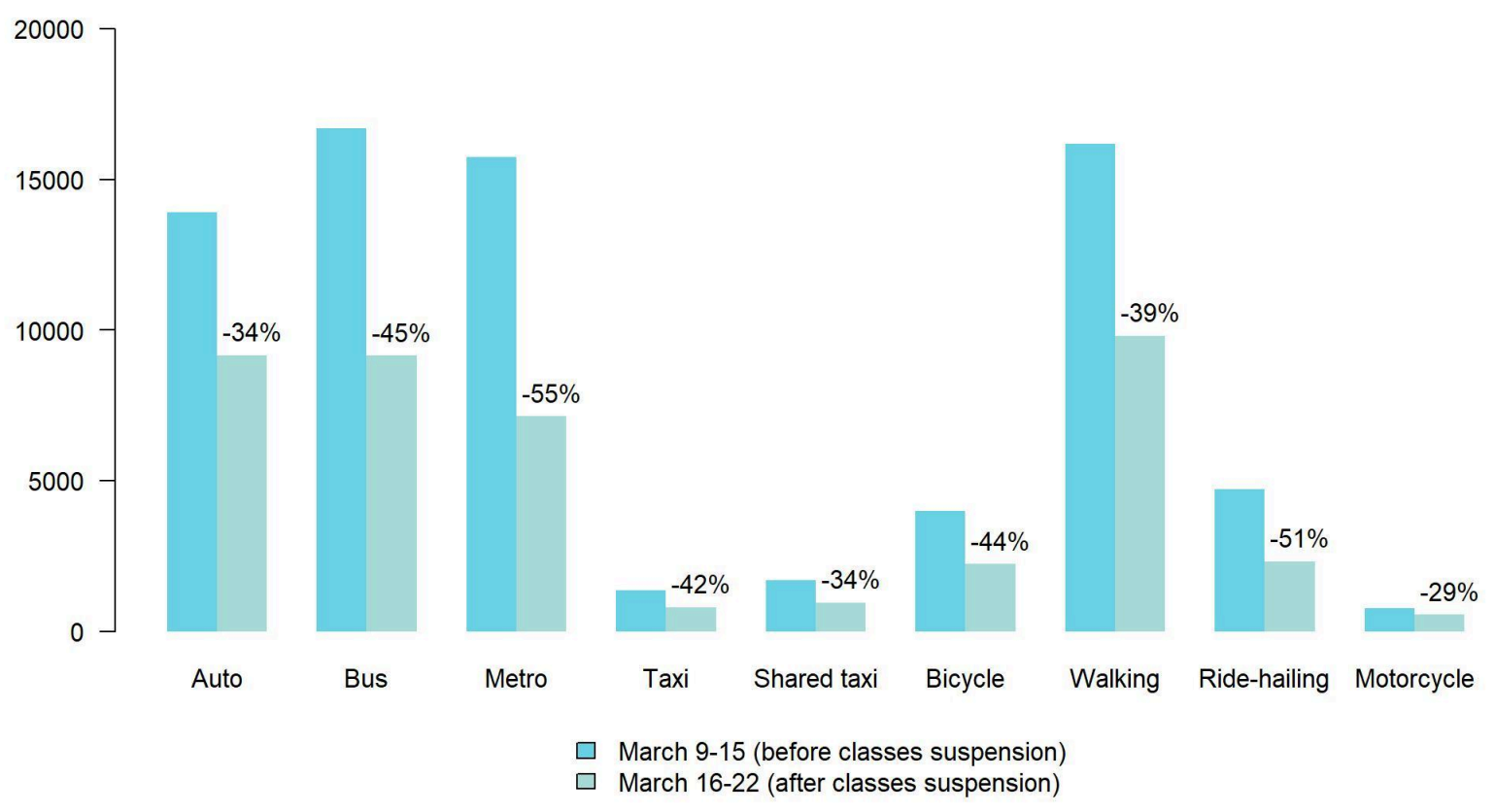

Figure 1: Total trips for Santiago sample $(\mathrm{n}=3,222)$

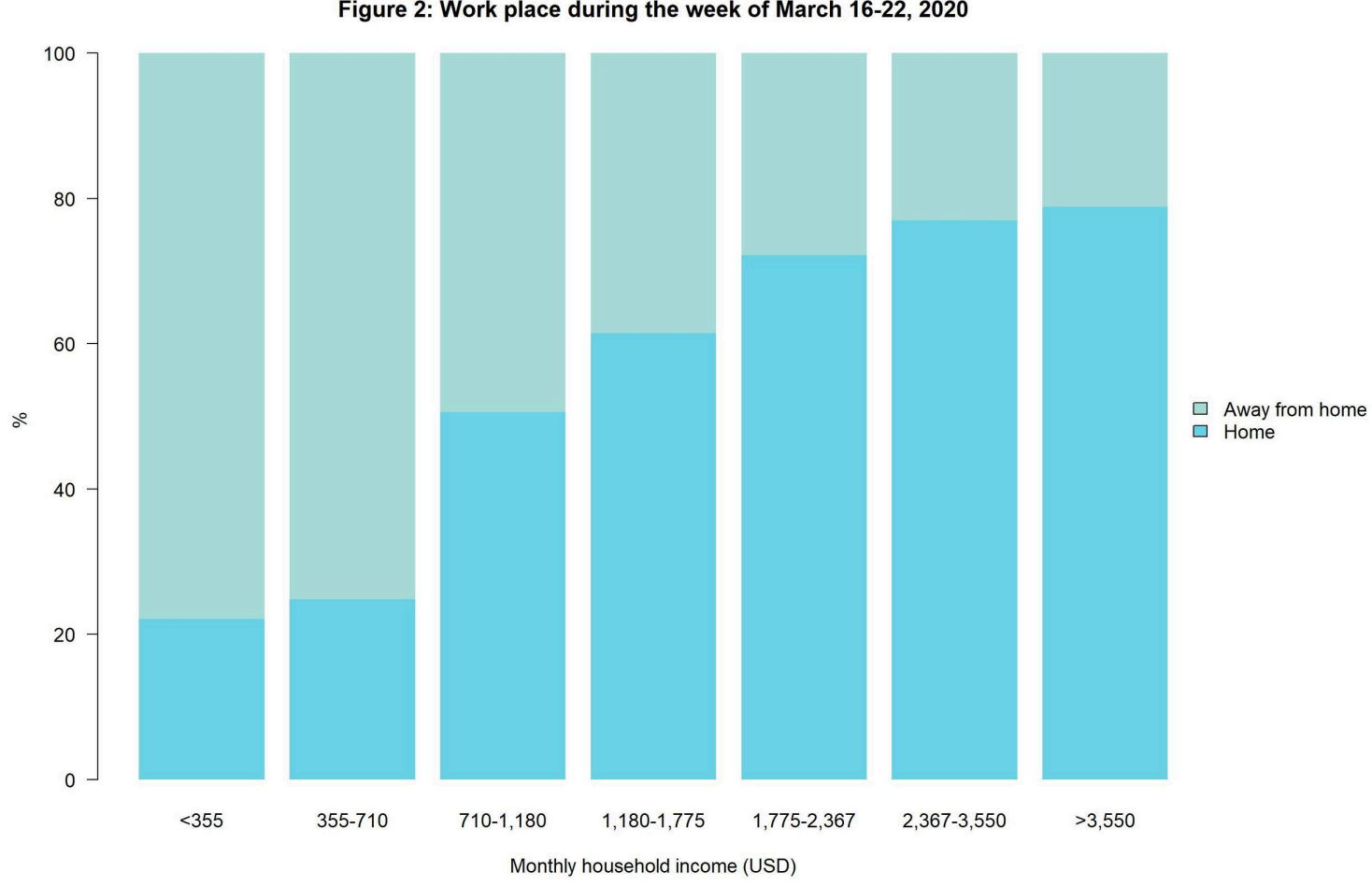

Figure 2: Workplace during the week of March 16-22, 2020 


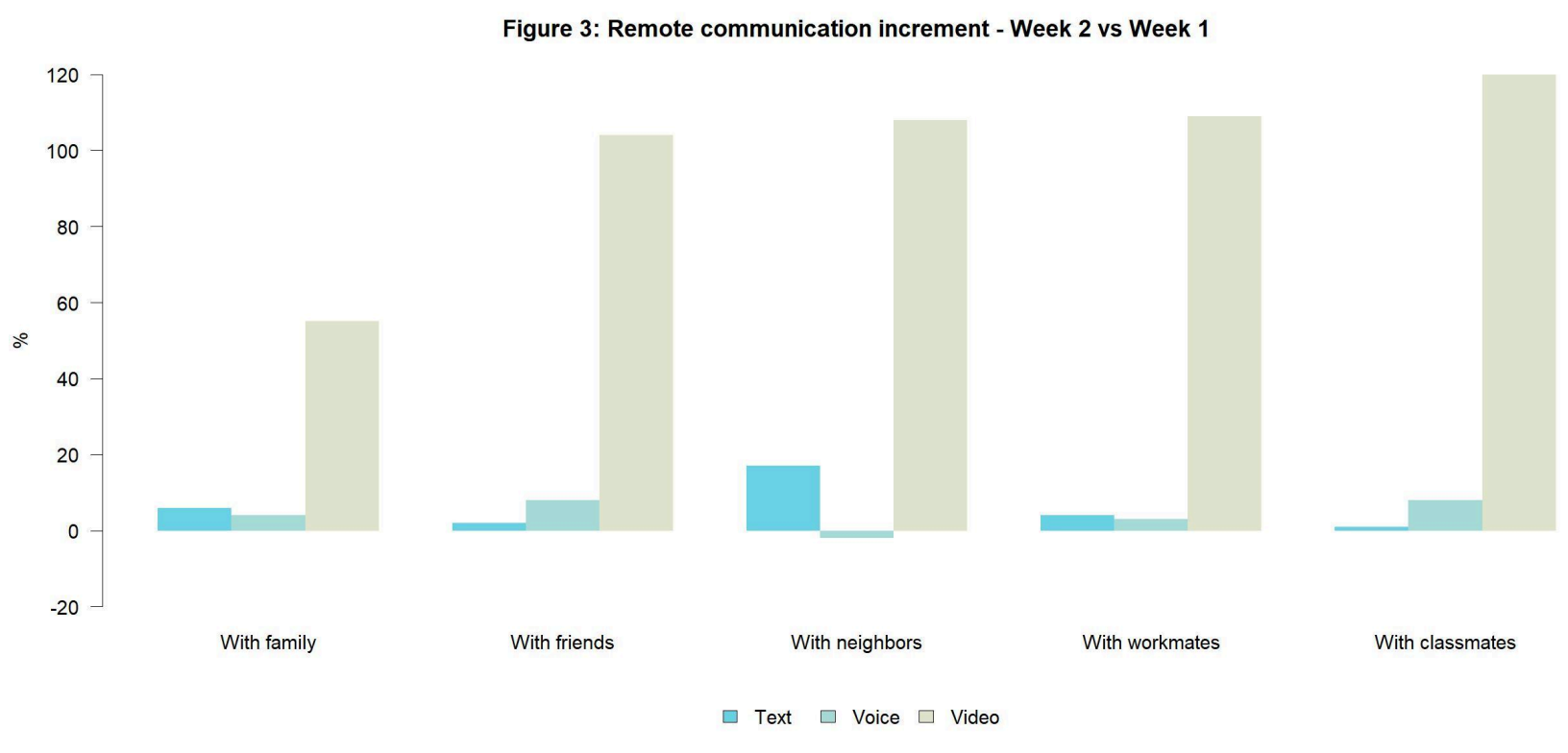

Figure 3: Remote communication increment - Week 2 vs Week 1

and voice calls decreased by $2 \%$. Notably, video communication increased $55 \%$ between relatives, and more than doubled between friends, neighbours, workmates, and classmates.

\section{MODEL ESTIMATION RESULTS}

Table 2 presents the estimation results of the joint model for workers from Santiago. Regarding the chances of teleworking (from home) during the pandemic, we highlight the following results:

- The income effect is confirmed (see Figure 2), even after controlling by other socioeconomic factors. ${ }^{3}$

- Higher educated individuals are more likely to work from home.

- Women are more likely to work from home than men. This might be related to the fact that the COVID-19 pandemic has a disproportionately negative effect on women's employment opportunities and obligations such as child-care (Alon et al. 2020).

- Healthcare workers and other essential services workers are more likely to work away from home than others, as expected. 
Table 2: Parameter estimates of the joint model for workers from Santiago

\begin{tabular}{|c|c|c|c|c|}
\hline \multirow{3}{*}{ Variable description } & \multicolumn{2}{|c|}{ Binary dependent variable } & \multicolumn{2}{|c|}{ Continuous dependent variable } \\
\hline & \multicolumn{2}{|c|}{$\begin{array}{l}\text { Work from home during Week } 2 \text { (base } \\
\text { is work away from home during Week } \\
\text { 2) }\end{array}$} & \multicolumn{2}{|c|}{$\begin{array}{c}\text { Difference in number of trips for } \\
\text { purposes other than work (Week } 2 \text { - } \\
\text { Week 1) }\end{array}$} \\
\hline & Coeff. & t-stat & Coeff. & t-stat \\
\hline Constant & -0.3529 & -3.22 & $-0.1364^{a}$ & -0.296 \\
\hline $\begin{array}{l}\text { Gender (base is Male) } \\
\text { Female }\end{array}$ & 0.3498 & 5.71 & -0.4367 & -1.98 \\
\hline $\begin{array}{l}\text { Age range (base is Between } 18 \text { and } 25 \\
\text { years old and Between } 36 \text { and } 45 \text { yea } \\
\text { old) } \\
\text { Between } 26 \text { and } 35 \text { years old } \\
\text { Between } 46 \text { and } 60 \text { years old } \\
\text { Older than } 60\end{array}$ & 0.1461 & 2.27 & $\begin{array}{l}1.0699 \\
1.9480\end{array}$ & $\begin{array}{l}3.27 \\
2.71\end{array}$ \\
\hline $\begin{array}{l}\text { Educational attainment (base is High- } \\
\text { school or less) } \\
\text { University degree } \\
\text { Post-graduate degree }\end{array}$ & $\begin{array}{l}0.4909 \\
0.6844 \\
\end{array}$ & $\begin{array}{l}6.01 \\
6.96 \\
\end{array}$ & & \\
\hline $\begin{array}{l}\text { Household income [USD/month] (bas } \\
\text { Less than } 710 \text { ) } \\
\text { Between } 710 \text { and 1,180 } \\
\text { Between } 1,180 \text { and } 1,775 \\
\text { Between } 1,775 \text { and } 3,550 \\
\text { More than } 3,550\end{array}$ & $\begin{array}{l}0.2209 \\
0.3657 \\
0.6821 \\
0.7081\end{array}$ & $\begin{array}{l}2.40 \\
3.61 \\
6.92 \\
6.17\end{array}$ & $\begin{array}{l}-0.5224 \\
-0.5224 \\
-0.7216 \\
-0.7981\end{array}$ & $\begin{array}{l}-2.70 \\
-2.70 \\
-2.92 \\
-2.90\end{array}$ \\
\hline $\begin{array}{l}\text { Employment status (base is Formal } \\
\text { dependent worker) } \\
\text { Formal independent worker } \\
\text { Informal worker }\end{array}$ & $\begin{array}{l}0.3046 \\
0.3950\end{array}$ & $\begin{array}{l}3.36 \\
3.12\end{array}$ & $\begin{array}{l}-1.2476 \\
-1.5096\end{array}$ & $\begin{array}{l}-3.84 \\
-3.09\end{array}$ \\
\hline $\begin{array}{l}\text { Essential worker status (bases is Not } \\
\text { essential worker) } \\
\text { Healthcare worker } \\
\text { Another basic service worker }\end{array}$ & $\begin{array}{l}-1.6931 \\
-0.8064\end{array}$ & $\begin{array}{l}-13.92 \\
-9.52\end{array}$ & & \\
\hline Household size & -0.0397 & -2.08 & $-0.1037^{b}$ & -1.91 \\
\hline $\begin{array}{l}\text { Endogenous effect } \\
\text { Work from home during the } \\
\text { pandemic }\end{array}$ & NA & NA & -2.0199 & -4.16 \\
\hline Standard deviation of the error term & 1.00 & (fixed) & 5.3971 & 43.7 \\
\hline Correlation between error terms & \multicolumn{4}{|c|}{0.318 (t-stat: 2.33 ) } \\
\hline
\end{tabular}

Estimation sample size 2,293

Log-likelihood null model: -20,511.8

Log-likelihood only constants model: $-18,529.0$

Log-likelihood final specification: $-8,376.3$

Adjusted $\rho^{2}$ w.r.t null model: 0.5903

Adjusted $\rho^{2}$ w.r.t. only constants model: 0.5465

All parameters significant at $5 \%$ level of significance unless otherwise noted.

NA: Not applicable

a: Not significant at any reasonable level

b: Not significant at $5 \%$ level of significance but significant at $10 \%$ level of significance 
- The larger the size of the household, the more likely workers work away from home. Among possible reasons for this result are that workers living in larger households tend to have higher financial obligations; they also have a higher probability of living with children, providing poorer conditions for teleworking.

Regarding the difference in the number of trips for purposes other than work, we highlight the following results:

- Women have a higher reduction of trips during the pandemic than men. This can be related to the fact that men might engage more in health-related risks during (and even prior to) the COVID-19 pandemic (Walter and McGregor 2020), implying more trips.

- Older than 46 years old individuals have a lower reduction in their number of trips during the pandemic than younger individuals, being this reduction even smaller for individuals older than 60. This is surprising since they are a great COVID risk group.

- Individuals from high-income households have a higher reduction of trips, probably because they have better access to delivery options and the financial capability to buy more in fewer trips and hire services at home.

- Individuals that work from home have a higher reduction in the number of trips for purposes other than work as well.

The correlation parameter is positive and significant, meaning that unobserved effects impact simultaneously and in the same direction to both decisions. Other important variables that were not significant in our joint model are self-reported health status, being in a high COVID risk group due to health conditions, auto-ownership, and individuals' evaluation of government's COVID policies, among others.

\section{ACKNOWLEDGMENTS}

The authors gratefully acknowledge financial support from ANID PIA/ BASAL AFB180003.

This is an open-access article distributed under the terms of the Creative Commons Attribution 4.0 


\section{REFERENCES}

Alon, Titan M., Matthias Doepke, Jane Olmstead-Rumsey, and Michèle Tertilt. 2020. "The Impact of COVID-19 on Gender Equality.” (No. w26947). National Bureau of Economic Research. https://doi.org/10.3386/w26947.

Álvarez, C., A. Cancino, C. Castillo, T. de Wolff, P. Gajardo, R. Lecaros, J. Ortega, A. Osses, H. Ramírez, and N. Valenzuela. 2020. "Report \#5: Scenarios for the Opening Schools during the Chilean COVID-19 Outbreak.” https://observatoriocovid19.sv/doc/biblioteca/internac/ Reporte5_CMM_AM2V_CEPS.pdf.

INE. 2018. “Encuesta Suplementaria de Ingresos 2017 (in Spanish).” Report. Chile: Instituto Nacional de Estadísticas (National Institute of Statistics).

Walter, Lauren A., and Alyson J. McGregor. 2020. "Sex- and Gender-Specific Observations and Implications for COVID-19.” Western Journal of Emergency Medicine: Integrating Emergency Care with Population Health 21 (3). https://doi.org/10.5811/westjem.2020.4.47536. 